\title{
Harrowing of sowings with synchronous additional fertilizing
}

\author{
Alexander Serguntsov ${ }^{1, *}$, and Nikolai Malashikhin ${ }^{2}$ \\ ${ }^{1}$ Department of processes and machines in agribusiness, Kuban State Agrarian University named after \\ I. T. Trubilin, 350044 Krasnodar, Russia \\ ${ }^{2}$ Department of machine and tractor fleet operation, 350044 Kuban State Agrarian University named \\ after I. T. Trubilin, Krasnodar, Russia
}

\begin{abstract}
There were offered the combination of technological operations for harrowing sowings of different crops at the same time with additional soil mineral fertilizing. On the example of field experience in 2017 in the educational farm "Kuban" of the Kuban State Agrarian University there was tested the effectiveness of various serial production machines for harrowing winter wheat variety Bagrat. In the control plot, harrowing of wheat after wintering was not carried out. The combination of technological operations in one pass of the machine-tractor unit on the field provides a reduction in the fleet of machines, its capital intensity, energy, material costs, and thus the increase the competitiveness of products. As a result of the research, there was offered a new technical support of processes, new working bodies for harrowing, a technological scheme of a multifunctional unit for combining the operations of additional fertilizing and harrowing of sowings, an experimental installation for research, there were studied the working conditions and quality indicators of the various working bodies on harrowing of sowings (uniformity of harrowing depth, structural and aggregate composition of soil after each option treatment of treatment). There was carried out the comparative analysis of the uniformity of harrowing depth of winter wheat crops compared with working bodies in the experiment, there was revealed the advantage of individual serial machines for harrowing crops. Mathematical processing of experimental data confirmed the effectiveness of the rotational harrow-hoe on all qualitative indicators (uniformity of harrowing depth, the coefficient of structural soil, etc.).
\end{abstract}

\section{Material and methods of the research}

The basis of successful cultivation of field crops is a strict compliance with the requirements of agricultural technologies [1] which provide the high-quality soil treatment, sowing of crops and their protection from weeds, diseases and agricultural pests. "Harrowing of good blossoming crops of winter wheat in the fall and spring plays the leading role among the agronomic measures against young weeds" [2, p. 414]. The purpose of harrowing of crops is to give the desired structure to the top of the arable layer, to

*Corresponding author: sasha2008_9191@mail.ru 
activate the biological and chemical processes in it, to align the field surface, to destroy the soil crust, seedlings and germs of weeds. There was also proved that with the help of preemergence and post-emergence crop harrowing of late spring crops up to $70 \%$ of weed vegetation can destroy, significantly reducing the cost of herbicides and improving the environmental situation. No damage of cultivated plants by the harrow teeth, soil poudrage and sprouting was provided by agronomic requirements to the crop harrowing.

\section{Results of the research}

Features of the design of medium and heavy teeth harrows inhibit the widespread use of such a valuable agricultural weed control method as harrowing crops. We need to start new high-speed machines for harrowing which don not reduce the quality of processing, they are rotary and spring harrows, striegels, rotary hoes (Fig.1) [4]. Also, the machines allow you to work at speeds up to $15-20 \mathrm{~km} / \mathrm{h}$, carefully align the soil surface, to destroy weeds and filamentous sprouts, soil crust, providing the access to air and moisture to the root system of plants. According to the recommendations harrows replace the sprayers for the destruction

of weeds

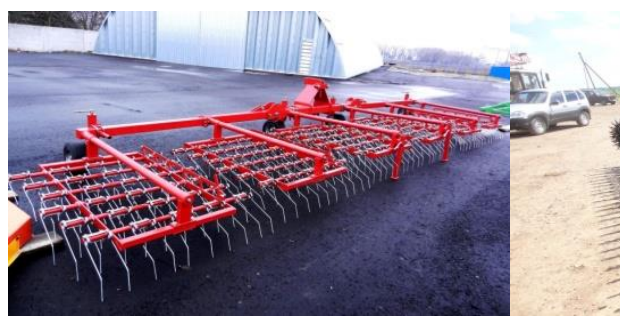

a)

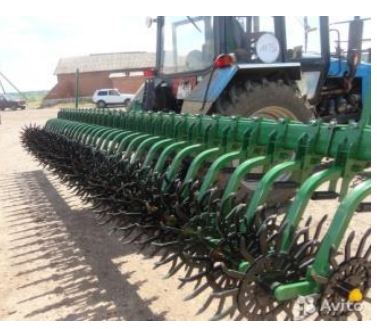

b)

[2].

Fig. 1. Modern complex of machines for crop harrowing: a) striegel; b) hinged rotary hoe.

A large set of equipment [4] for harrowing sets the task of choosing the best alternative option in the specific prevailing conditions. Making a decision, the best criterion, in our opinion, is the value of the crop for each option, but you can use some intermediate criteria for assessing options: the degree of damage to cultivated plants, the completeness of weed destruction, the equalization of soil surface, the uniformity of the depth of processing, the presence of valuable agronomic units, etc.

2. In our small-scale experience there was set the task to reveal the best option of crop harrowing to obtain the winter wheat. The experiments were laid out in 2017 at the experimental field of the Kuban State Agrarian University according to the method of B. A. Dospekhov [5]. The characteristic of the experiment plot is shown in Table 1 and the scheme of the experiment is shown in Figure 2.

Table 1. Characteristic of the plot.

\begin{tabular}{|l|c|}
\hline \multicolumn{1}{|c|}{ Characteristic } & Value \\
\hline 1. Winter wheat variety & Bagrat \\
\hline 2. Soil type & $\begin{array}{c}\text { West-Ciscaucasian leached } \\
\text { chernozem }\end{array}$ \\
\hline 3. Predecessor & Corn for grain \\
\hline 4. Main soil processing & $\begin{array}{c}\text { Disking on depth in } 10-12 \mathrm{~cm} \mathrm{в} \\
\text { in two passes }\end{array}$ \\
\hline 5. Main fertilizing & not introduced \\
\hline 6. Prevernal additional fertilizing, $\mathrm{kg}$ & 34,5 \\
\hline
\end{tabular}




\begin{tabular}{|c|c|c|}
\hline Characteristic & \multicolumn{2}{|c|}{ Value } \\
\hline 7. Winter wheat sowing rate, $\mathrm{mln}$.grains/ha & \multicolumn{2}{|c|}{5} \\
\hline 8. Depth of seed embedding, $\mathrm{cm}$ & \multicolumn{2}{|c|}{$4-5$} \\
\hline 9. Plant development phase before additional fertilizing & \multicolumn{2}{|c|}{ tillering } \\
\hline 10. Winter wheat sowing date & \multicolumn{2}{|c|}{20.10 .2016} \\
\hline 11. Sowing harrowing date & \multicolumn{2}{|c|}{02.03 .2017} \\
\hline 12. Plot infestation on 02.03 .2017 & \multicolumn{2}{|c|}{ absent } \\
\hline 13. Presence of stubble residues in sowings, $\mathrm{g} / \mathrm{m}^{2}$ & \multicolumn{2}{|c|}{323,9} \\
\hline $\begin{array}{l}\text { 14. Density of Winter wheat plant population, } \mathrm{mln} . / \text { ha } \\
\text { (by young growth) }\end{array}$ & \multicolumn{2}{|c|}{3,96} \\
\hline \multirow{2}{*}{ 15. Soil hardiness before harrowing, $\mathrm{MPa}$} & $0-5 \mathrm{~cm}$ & 0,14 \\
\hline & $5-10 \mathrm{~cm}$ & 0,53 \\
\hline 16. Soil moisture in the layer $0-10 \mathrm{~cm}, \%$ & \multicolumn{2}{|c|}{26,4} \\
\hline
\end{tabular}

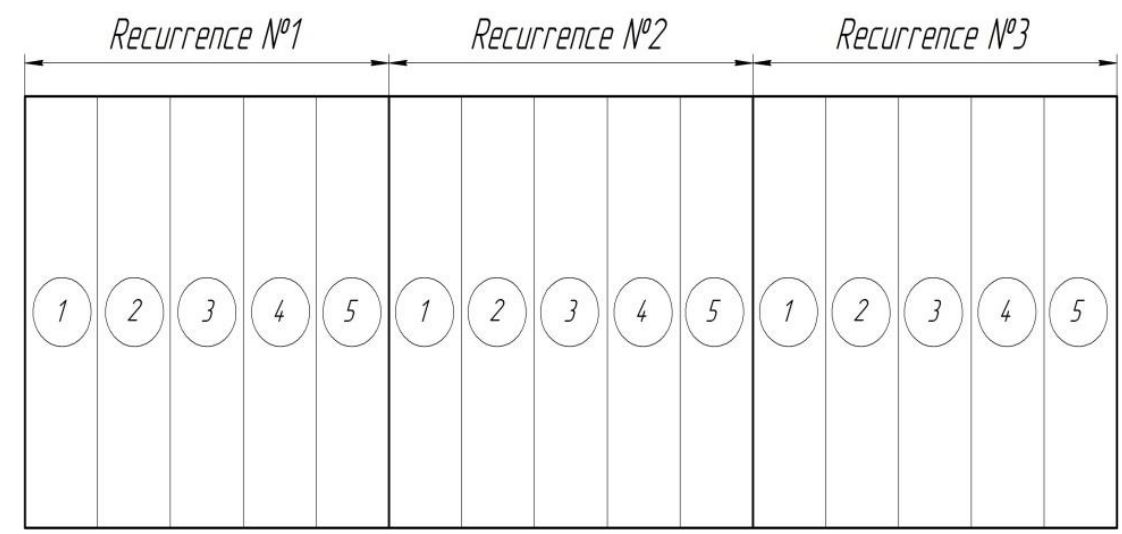

Fig. 2. The experimental scheme with the harrowing of winter wheat by different machinery: 1 rotary hoe with active location of teeth; 2 rotary hoe with passive location of teeth; 3 - harrow ZBP-0,6; 4 control (harrowing free); 5 - drill seeder "Klyon 1.5".

A variant with a grain drill "Klyon and 1.5" is also included in the experimental scheme, since according to the farming system [3, p. 177] the most high quality distribution of mineral fertilizers on the field and adherence of dosing are provided using grain drills, aviation and centrifugal type fertilizer spreaders. The radical additional fertilizing by grain drills is more effective when drying the top layer of soil.

Recommended options of winter wheat fertilizing in farming systems [3] do not take into account the combined the combined option of fertilizing simultaneously with harrowing of winter wheat, which are the objectives of our research.

There was chosen the experimental plot which was sown with winter wheat variety Bagrat. The type of soil is West-Ciscaucasian leached chernozem, predecessor is maize for grain, main tillage is disking of stubble in two tracks to a depth of 10-12 cm. Fertilizers were not introduced under the basic treatment but nitric fertilizers with the norm of $30 \mathrm{~kg}$ were introduced in spring additional fertilizing. Sowing date of winter wheat was October 20, 2016, the date of the spring harrowing was March 2, 2017. There was no sowing infestation, the density of wheat standing was 4 million seedlings on 1 ha, the presence of stubble residues on the field in $323 \mathrm{~g} / \mathrm{m} 2$, the hardness of soil in the $0-5 \mathrm{~cm}$ layer was 0.14 $\mathrm{MPa}$, in the layer of $5-10 \mathrm{~cm}-0.53 \mathrm{MPa}$, soil moisture in the layer of $0-10 \mathrm{~cm}$ was $26.4 \%$.

Harrowing was made with the use of our experimental machine (Fig.3). 


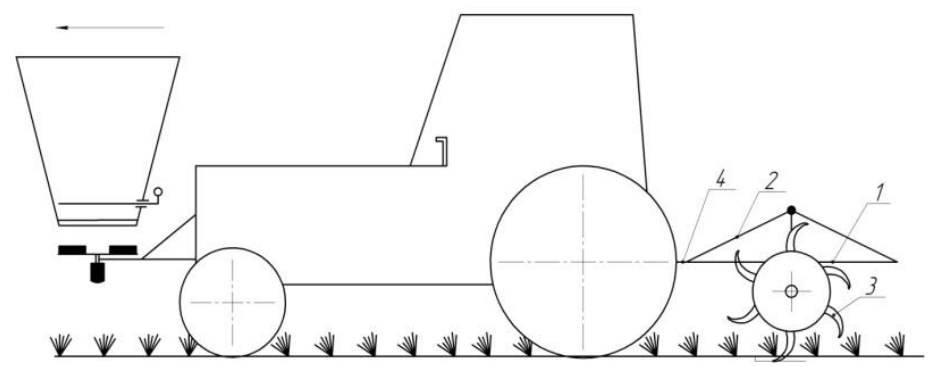

Fig. 3. General view of the experimental machine: 1-frame; 2-hinged device; 3 - replaceable working bodies for harrowing; 4-blackets for dynamometering.

The experimental machine with replaceable working bodies was aggregated with the MTZ-80 tractor. Each option under the scheme of the experiment (Fig.2) is laid in threefold replication. The location of plots is systematic.

During the experiment on each option (except control) there was measured the depth of tillage with the determination of uniformity, the working speed of the unit movement, the aggregate soil composition, dynamometry of the working bodies of the rotary harrow followed by the determination of the specific traction resistance.

The uniformity of tillage depth under winter wheat harrowing by different working bodies are shown in Table 2.

Table 2. The uniformity of tillage depth under harrowing by variants + )

\begin{tabular}{|l|c|c|c|c|}
\hline \multicolumn{1}{|c|}{ Variants of experience } & $\begin{array}{c}\text { Mathematical } \\
\text { expectation, Msr , mm }\end{array}$ & $\pm \sigma, \mathrm{mm}$ & $\mathrm{V}, \%$ & $\mathrm{P}, \%$ \\
\hline $\begin{array}{l}\text { 1.Rotary hoe with active disposition } \\
\text { of teeth }\end{array}$ & 45,9 & 5,13 & 11,2 & 1,6 \\
\hline $\begin{array}{l}\text { 2. Rotary hoe with passive disposition } \\
\text { of teeth }\end{array}$ & 27,5 & 4,6 & 16,7 & 2,4 \\
\hline 3. Teeth sowing harrow ZPB-0,6 & 17,1 & 5,7 & 33,3 & 4,7 \\
\hline 4. Sowing machine «Klyon-1,5» & 32,6 & 6,9 & 21,1 & 3,0 \\
\hline
\end{tabular}

+) $\sigma$ - RMS divergence; $\mathrm{V}$ - coefficient of variant; $\mathrm{P}$ - relative error of mean proportional.

The error of the selective mean for the variants of experience (Table.2) did not exceed $4.7 \%$. The greatest tillage depth amounted to $45.9 \mathrm{~mm}$, followed by the plows of the grain drill $(32.6 \mathrm{~mm})$, then disks of the rotary harrow $(27.5 \mathrm{~mm})$ and seeding harrow $(17.1 \mathrm{~mm})$. Coefficient of variation $\mathrm{V}$ is characterized by the uneven depth of processing, having a satisfactory value $(11.2-21.1)$, except for the sowing harrow ZBP-0.6 (33.3\%). The operating speed was in the range of $8-10 \mathrm{~km} / \mathrm{h}$.

The rotary harrow with an active disposition of teeth (both by the coefficient of variation, and by the accuracy of experience) provided the best tillage depth, therefore its use in harrowing of winter wheat crops is most preferable due to indicators specified in Table 2.

The most important sign of the soli tillage is its structural and aggregate composition in the processed layer (Table.3). It is a sign of soil fertility. Determination of structural and aggregate composition of the soil was carried out by the method of N. I. Savvinov.

As already noted, the tasks after sowing are to create favorable conditions for the germination of seeds, to give the desired structure to the top of the arable layer, to destroy weeds. Harrowing of crops is carried out in order to facilitate the growth of plants by tillage of compacted soil layer and to destroy the formed crust. At the same time weeds are also destroyed. Harrowing evens the soil surface, promotes the germination of more weeds that can be destroyed by re-harrowing or using herbicides. The compacted top layer of the soil, 
which is unstructured, prevents the flow of water and air into the lower layers. As a result, moisture is lost: during the rains not absorbed water flows into low places, causing erosion and waterlogging.

In some cases, harrowing before and after germination in combination with the optimal sowing period provides the same degree of weed loss as in the use of soil herbicides. It was checked on sunflower in our region [3, page 231].

The structural and aggregate composition of the soil did not differ significantly according to the obtained results of winter wheat harrowing in different variants (Table.3). A common disadvantage for all options of harrowing is the failure of agricultural requirements for the most important indicator - the presence of the most valuable agronomic fractions of $3 \mathrm{~mm}$, which should be in the treated layer on at least 80\% [7].

Table 3. Structural-aggregate soil content under winter wheat harrowing on experimental variants.

\begin{tabular}{|c|c|c|c|c|c|c|c|}
\hline \multirow{3}{*}{ Variants } & \multicolumn{6}{|c|}{ Fraction size } & \multirow{3}{*}{$\begin{array}{l}\text { Coefficient of } \\
\text { structural } \\
\text { properties }\end{array}$} \\
\hline & \multicolumn{2}{|c|}{ to $1 \mathrm{~mm}$} & \multicolumn{2}{|c|}{$1-3 \mathrm{~mm}$} & \multicolumn{2}{|c|}{ over $3 \mathrm{~mm}$} & \\
\hline & mass, $g$ & $\%$ & mass, $g$ & $\%$ & mass, $g$ & $\%$ & \\
\hline $\begin{array}{l}\text { 1. MPH } \\
\text { (active tooth) }\end{array}$ & 91,5 & 9,2 & 557,1 & 55,7 & 351,4 & 35,1 & 4,25 \\
\hline $\begin{array}{l}\text { 2. MPH } \\
\text { (passive tooth) }\end{array}$ & 81,0 & 8,1 & 550,0 & 55,0 & 369,0 & 36,9 & 4,11 \\
\hline 3. ZBP- 0,6 & 73,7 & 7,4 & 498,1 & 49,8 & 428,2 & 42,8 & 2,76 \\
\hline 4. Klyon-1,5 & 66,9 & 6,7 & 504,9 & 50,5 & 428,2 & 42,8 & 3,02 \\
\hline 5. Control & 51,0 & 5,1 & 486,6 & 48,7 & 462,4 & 46,2 & 2,49 \\
\hline
\end{tabular}

In our experience, the maximum number of agrotechnically useful fractions was $55.7 \%$, which is not sufficient and sets the task of intensifying the tillage process due to the proposed new design of the tooth of the rotary hoe (Fig.4)

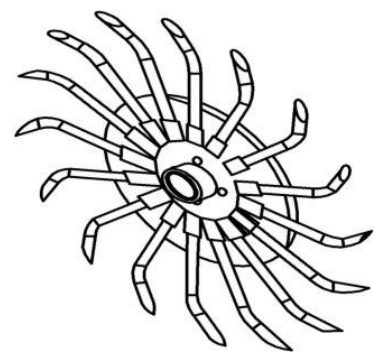

Fig. 4. Proposed construction of rotary harrow tooth

The proposed rotary working body of the tillage tool contains a disk with a hub and needles fixed on it, made of spring steel. At the end of each needle facing the center of the disc, there was made an oblique cut at an angle $\alpha$, not exceeding the amount of friction angle of steel on the soil. The needle rod with a certain tension is pressed into the hub attached to the disc. At the periphery of the disc, each needle is fixed, for example, by welding [6].

The advantages of the proposed design are the reduction of energy intensity of soil treatment and simplification of the design of the working body. It is achieved by the fact that the rotary working body of the tillage tool containing a disk with needles placed on it, which is made of spring steel, according to the invention, the end of each needle is provided with an oblique cut at an angle $\alpha$ not exceeding the friction angle of the soil, and the needle rod is pressed into the hug fastened to the disk and fixed on its periphery, while the needle has a length providing a kinematic mode in the range 0.66-1.0. 


\section{Conclusions}

Following the obtained results, the interval of the kinematic regime index in our studies was 0.66-1.0. The index of kinematic regime is the ratio of circumferential speed of the working body (disk) to $\mathrm{m} / \mathrm{s}$ of progressive speed of the unit in $\mathrm{m} / \mathrm{s}$. The quality of soil crumbling, the evenness of the furrow bottom and the energy costs to this operation depends on this indicator. The length of the needle determines the diameter of the disc, and the latter is the value of its circumferential speed.

\section{References}

1. L.M. Pilyugin, Standard technological maps of cultivation and harvest of cereal crops (Moscow, 1984)

2. A. A. Zhuchenko, Agriculture systems of Stavropol (Stavropol, 2011)

3. A. N. Korobka, System of farming of Krasnodar region on landscape basis (Krasnodar, 2015)

4. Soil cultivating machines for resource - and energy-saving technologies STRIEGEL / Krasnodar@yugprom.ru.

5. B.A. Dospekhov, Method of field experiment (Moscow, 1979)

6. G. G. Maslov, A. S. Serguntsov, The unit for soil processing and fertilizers (Patent for the invention RUS 2629265)

7. V. I. Aniskin, Initial requirements for basic machine technological operations in crop sector (Moscow, 2005) 